\title{
KIPÇAKÇADA SÜT VE SÜT ÜRÜNLERİ İLE ÍLGILI SÖZVARLIĞI
}

\author{
Ayşe Şeyma FINDIK*
}

\begin{abstract}
ÖZET
Kıpçakça 13-15. yüzyıllar arasında Karadeniz'in kuzeyinde (bugünkü Rusya, Ukrayna, Kafkaslar), Mısır ve Suriye'de yazı dili olarak kullanılmışırı. Kuzeybatı grubuna mensup olmasına rağmen, 12. yüzyılda Kıpçakların Mısır’a köle olarak gitmelerinden dolayı, Mısır ve Suriye coğrafyasında da yayılma sahası bulmuş ve bu coğrafyada konuşulan dil Memluk Kıpçakçası olarak sınıflandırılmıştır. Birçok eser Arapların Türkçeyi öğrenmelerini kolaylaştırmak amacıyla yazılmıştır. Yazılan eserlerin büyük çoğunluğu sözlük ve gramer kitaplarından oluşmaktadır. Türk kavimlerine hayvancıllğın Ön Asya'dan ve Harezm yoluyla girdiği ve hayvanları evcilleştiren ve geliştiren bölgelerin başında Orta Asya'nın geldiği bilinmektedir. Süt ürünlerinin sözvarlığının Türk boylarında değişiklik göstermesinin sebepleri olarak saklama koşullarının farklı olması, sütün cinsi, sütün diğer malzemelerle oranı, pişme biçimi olarak sayılabilir. Bu çalışmada süt ve süt ürünleriyle ilgili sözvarlığı tarihi Kıpçakça dönemine ait eserler aracılığıyla incelenmiş, tarihi Türk dilleri ve çağdaş Kıpçakçadaki kullanım durumuna bakılmıştır. Karadeniz'in kuzeyinde Latin harfli olarak tüccarlar için yazılmış olan Codex Cumanicus'ta süt ürünleri ile ilgili sözvarlığına rastlanmadığından dolayı çalışma içinde sözlüğün ismi zikredilmemiştir. Çağatayca dönemine ait yalnızca sözlüklere bakılmış olup, sözcüğün edebi eserlerde geçip geçmediği bilgisine yer verilmemiştir. Sözcük hakkında etimoloji sözlüklerinde yer alan görüşler de ayrıca sunulmuştur.
\end{abstract}

Anahtar Kelimeler: Kıpçakça, Süt, Süt Ürünleri, Çağdaş Kıpçakça

\section{VOCABULARY ABOUT MILK AND DAIRY PRODUCTS IN QIPCHAK}

\begin{abstract}
Qipchak language was used as a written language in the north of the Black Sea (today's Russia, Ukraine, the Caucasus), Egypt and Syria between 13th-15th century. Although it is a member of the North-western group, it found a spreading area in Egypt and Syria because Qipchaks went to Egypt as slaves. After that the language which had been spoken in this area was categorized Memluq Qipchak. Many works were written with the aim of making it easier for Arabs to learn Turkish. Most of the written works are dictionaries and grammar books. It is known that livestock farming was entered to the Turkish tribes through Asia Minor and the Harezm and also Central Asia is one of the major regions that domesticate and develop animals. Different storage conditions, type of milk, ratio of milk with other ingredients, cooking style can be considered as the reasons for the variation in vocabulary of dairy products in Turkish tribes. In this study, the vocabulary related to milk and dairy products was examined through the works of the historical Qipchak period and the historical Turkish languages and the usage situation in modern Qipchak. There is no vocabulary related to dairy products in Codex Cumanicus written in Latin letters for merchants in the north of the Black Sea, so the dictionary name was not mentioned in the study. Only the dictionaries belonging to the Chagatay period were examined and no information was
\end{abstract}

\footnotetext{
* Arş. Gör., Fatih Sultan Mehmet Vakıf Üniversitesi, Türk Dili ve Edebiyatı Bölümü, e posta: asfindik@fsm.edu.tr, ORCID: 0000-0002-1090-6354
} 
given whether the word was mentioned in literary works. The opinions in etymology dictionaries about the words were also presented.

Key Words: Qipchak, Milk, Dairy Products, Modern Qipchak

\section{GíRiş}

Kumanlar ve Kıpçaklar 8. yüzyılda Göktürk Devleti'nde yer alan Türk boylarındandı. Savaşlar ve göçler sonunda Kıpçak adı altında birleşerek, 11. yüzyılda İdil Nehri'ni geçip batıya göç etmişlerdir. 13. yüzyılda Kıpçakların bir kısmı Mısır'a giderek paralı olarak görev yapan askerler olmuşlardır. 1250 yılında Kıpçaklar tarafından kurulan Memluk Devleti'nin çatısı altında Memluk Kıpçakçası ile pek çok eser yazılmıştır. Bu eserler Arap olan halka Türkçeyi öğretme amacıyla yazılmış olup yabancılara Türkçe öğretiminin izleri bu dönemde görülmüştür. Yazılan eserlerin büyük çoğunluğu gramer ve sözlüklerden oluşmaktadır. Bunların dışında at bakımı, okçuluk, fikı gibi konularda da eserler verilmiştir. Yazılmış olan sözlüklerden dönemin sözvarlığının oldukça zengin olmasından, kimi kelimelerin sadece bu dönemde görülmesinden dolayı süt ürünleriyle ilgili söz varlığı özellikle Kıpçakça eserlerde taranmıştır ve bu çalışmayı oluşturmuştur.

\section{SÜT VE SÜT ÜRÜNLERİ ILE İLGILİ SÖZVARLIĞI}

1. avuz aġuz "deve ve koyunun ilk sütü” (Toparl, 2007: 17) Kıpçak BM avuz "doğumdan sonra deve veya koyunun ilk sütü" $8 / 3$; avuz "süt fermantasyon mayası" 8/17 (Zajaczkowski, 1958: 9); TZ avuz "ilk süt, ağız" 31b/13 (Atalay, 1945: 145); Kİ ag்uz/ovuz "koyun ve emsalinin doğurduğu zaman ilk sütünden yapılan yoğurt" 17 (Caferoğlu, 1931: 2)

Tarihi: KökT.-, Uyg.-, MK ağuj "ağız, inek veya koyun doğurduktan sonra ilk gelen süt" (DLT I, 55-9), Tefsir og̉uz igi "göğüs iltihabı" (Usta, 2002: 199), Harezm ME-, NF-, KE- , Çăg. Seng. ag்uz 44r/9; Courteille ag்uz "çocuk doğurduktan sonra gelen ilk süt” 26

Clauson, ag்uj/ağuz için "doğumdan sonra inek ya da benzeri hayvanların memelerinde hızlıca oluşan süt, doğumdan sonra oluşan ilk süt" anlamını vermiştir. Dîvân-1 Lugâti't-Türk'te kelime $a \dot{g} u j$ olarak yazılmıştır fakat -z ile de telaffuz edilebileceği belirtilmiştir. (EDPT: 98a)

Hasan Eren $a \breve{g ̆} z(2)$ için "yeni doğurmuş ineğin ilk sütü” anlamını vermiştir. Bunun yanı sıra Türkçeden Moğolcaya uğurağ, uğuruğ olarak geçtiğini belirtir ve Ramstedt'in aynı doğrultudaki görüşüne yer verirken (Eren, 1999, s.5), Doerfer ise Türkçe ă̆uz kelimesinin Moğolca ağură̆ ile aynı olduğunu ve göçebe kültürüyle ilgili bir söz olduğunu belirtmiştir. (TMEN II 501: 80) 
Kelime İslam öncesi kaynaklarda, Budist çevreye ait olan-olmayan metinler dahil DLT'den önce hiçbir kaynakta görülmez. Ayrıca DLT'de son ses -j olarak geçer.

Çağdaş Kıpçak: Tat. ugız "ağız” (TatRS1: 466), Başk. ıwız “ağız” (BaşkRS1: 674), Kzk. uwız "yavrulayan hayvanın ilk sütü" (KzkRSl: 289), Nog. uvız "ağız" (NogRSl: 379), KBalk. uwuz "ağız, kolostrum" (KBalkRSl: 689), Kum. uvuz "kolostrum" (KumRSl: 330), Karay.-

Bahaeddin Ögel'in bu kelime hakkındaki görüşleri şöyledir: "Eski Türkçede ă̆uz, $a v u z$ yeni doğuran memeli hayvanların verdikleri ilk süt için söylenen bir sözdür. Ağız sözü yalnız hayvanlar için değil, ilk ana sütü için de kullanılırdı. Paassonen'e göre Çuvaş ağzındaki şevar sözü bile, ses değişmeleri yolu ile meydana gelmiş, Türkçe “ağız” sözünden başka bir şey değildir.” (Ögel, 1978: 9) Ancak Ögel'in görüşü Çuvaşça üzerine yeni yayımlanmış çalışmalarla genişletilmelidir.

Derleme Sözlüğünde bu kelime için "yeni doğurmuş hayvanın ilk sütü; yeni doğurmuş hayvanın sütünden yapılan bir çeşit yiyecek; yeni doğurmuş hayvanın sütünden yapılan bir tatlı, yağlı peynir; yeni doğurmuş hayvanın ilk sütüyle yapılan ekmek; yeni doğurmuş hayvanın ilk sütünden yapılan yoğurt" anlamları verilmiştir. (DS 1993: 115-116)

2. ayran "ayran" (Toparl1, 2007, s.18) Kıpçak TA ayran "ayran" 17b/1 (Toparl1, 2000: 90); TZ ayran "ayran" 31b/12 (Atalay, 1945: 145); BM ayran "kesilip koyulaşmış süt" 8/3 (Zajaczkowski, 1958: 6); GT ayran "ayran" 85/3 (Karamanlıoğl1,1989: 209); DM ayran “ayran” 4b/4 (Toparl1, 2018: 73)

Tarihi: KökT.-, Uyg.-, DLT ayran "ayran” (DLT I, 120-26), Harezm ME-, NF-, KE-, Çağ. Courteille ayran "kesilmiş sütün suyu" 107; LÇ ayran "ayran" 48L/3; Seng. ayran $57 \mathrm{r} / 17$

Clauson kelimenin kökünün ayr- (adֵr-)' dan geldiğini düşünmüştür ve kelimeye uzun ünlülü olarak ayrān biçiminde yer vermiştir. $\mathrm{Bu}$ ses değişiminin tuhaf olduğunu ve Karahanlı döneminde meydana gelmiş olduğunu ileri sürmüştür. Ayrak ve ayran olarak aynı anlama gelen iki farklı kelime olduğunu belirtmiştir. Ayrak in Türkçede bilinmediğini, kelimenin Moğolca ayirak olduğunu ve Türkçeden ödünçleme olduğunu savunmuştur. (EDPT: 276a) Moğolca sözlükte airag "kımız, kısrak veya ineğin mayalanmış sütü" anlamında verilmiştir. (Lessing, 2003: 21)

Doefer ise kelimenin anlamını "mayalanmış (fermente olmuş) inek sütü" olarak vermiş, kelimenin kökeninin Türkçe olduğunu, Türkçeden Moğolcaya geçtiğini, sonra da Moğolcadan Türkçeye geçtiğini belirtmiştir. (TMEN II 639: 179)

Çağdaş Kıpçak: Tat. eyren "ayran" (TatRSl: 170), Başk. ayran "ekşimiş süt" (BaşkRSl: 26), Kzk. ayran "ayran" (KzkRSl: 9), Nog. ayran "ayran, ekşimiş süt" 
(NogRSl: 30), KBalk. ayran "ayran" (KBalkRSl: 34), Kum. ayran "ayran" (KumRsl: 33), Karay. ayran "ayran” (KarayRSl: 54)

Orhan Şaik Gökyay, Radloff'un "Aus Sibirien” adlı kitabından aktararak, Altaylılarda sağılır sağılmaz kaynatılarak tulumlara doldurulan ve ekşimeye bırakılan inek sütünün ayran adını aldığını belirtmekte, içilme yollarını ve ayranla yapılan yemekleri anlatmaktadır. (Aksan, 2008: 127)

3. çıḳıt çığıt "peynir" (Toparlı, 2007: 50) Kıpçak TZ çıkıt "peynir" 11b/10, (Atalay, 1945: 162); TA çı̆̆lt "peynir" 17b/2 (Toparl1, 2000: 100)

Tarihi: KökT.-, Uyg.-, DLT-,Harezm ME-, NF-, KE-, Çağ.-

Tuhfetu'z-Zekiyye'de bu kelime için “Türkmenler buna peynir derler" açıklaması yapılmıştır. Tarihi dönemde kelimeye rastlanmamıştır. Çağdaş Kıpçak dillerinden sadece Karayimce'de yer alır: çığıt "süzme peynir" (KarayRSl: 635)

Hasan Eren bu kelimenin Osetçe'den gelmiş olabileceğini başka kaynaklara dayanarak dile getirmiştir. (Eren,1999: 456)

4. göremez Fa. "süt çalınmış yoğurt, bir tür peynir” (TOPARLI 2007: 87) Kıpçak İH göremez 25 (İZBUDAK 1989: 21)

Tarihi: KökT.-, Uyg.-, DLT-,Harezm ME-, NF-, KE-, Çağ.-

Hasan Eren bu kelime için "taze sütle ekşi sütün yoğurt biçimindeki karışımı" anlamını vermiştir. Kelimenin Farsçada gormâst olduğunu ve anlamının "yabani eşek sütünden yapılan taze peynir" (gor: yabani eşek, mâst: kesik ağdalanmış süt) olduğunu belirtmiştir. Türkçe göremez biçiminin ortasında görülen $e$ sesinin ikincil bir ses olduğunu ve Farsça gormast'ın sonundaki $t$ 'nin Türkçede düştügünü belirtmiştir. Türkçeden Arnavutçaya gjeremes "kesik süt" şeklinde geçmiştir. (Eren, 1999: 163)

Çağdaş Kıpçak dillerinde yer almamaktadır.

Bu sözcük, Derleme Sözlüğü’nde gölemez (gölmez) biçiminde yer almış olup anlamları ise "yeni doğurmuş hayvanın ilk sütü; yeni doğurmuş hayvanın ilk sütü ile yapılmış tatlı; sonbaharda hayvanlardan elde edilen koyulaşmış süt; içine ekmek doğranmış süt; yağı alınmış çiğ süt; ekşitilmiş süt; sütün içine bir çeşit ot suyu konularak yapılan yoğurt; yeni doğurmuş hayvanların sütlerine dövülmüş keçi boynuzu ve şeker katılarak yapılan bir çeşit tatlı” olarak verilmiştir.(DS 1993: 2143)

5. irimçik yürümçik "peynir” (Toparlı, 2007: 333) Kıpçak TA yürümçik "peynir" 17b/2 (Toparl1, 2000: 161); TZ irimçik “yoğurt yapmak için kaynatılırken kesilmiş olan süt” 31b/33 (Atalay, 1945: 179) 
Tarihi: KökT.-, Uyg.-, DLT-, Harezm ME-, NF-, KE-, Çağ. Courteille irimçik "bir çeşit peynir" 109

Çağdaş Kıpçak: Tat. eremçek "süzme peynir" (TatRSl: 671), Başk. eremcek "süzme peynir" (BaşkRSl: 685), Kzk. irimşik "kesilmiş sütün kaynatılması ile elde edilen bir süt ürünü” (KzkRS1: 327), Nog. irimşik "süzme peynir" (NogRS1: 120), KBalk.-, Kum.-, Karay. çırımçık “süzme peynir” (KarayRSı: 638)

Peynir manasına gelen diğer Türkçe bir sözcük ise irimçik deyişidir. İrimçik deyişi de ilk önce Misır Memluk Türkçesinde görülmüsştür. Fakat Batı Türklüğünde görülen bu deyiş henüz daha tam manası ile peynir için kullanılmamaktadır. Daha çok yoğurt yapmak için süt kaynatılırken kesilmiş olan süte bu ad verilmiştir. Halbuki Orta Asya lehçelerinde irimçik doğrudan doğruya peynir demektir. Bahaeddin Ögel, irim sözcügüunün Türkçede girdap, çevrinti manasına geldiğini ve peynirin şeklinden dolayı bu ismi alabileceğini söylemiştir. Nitekim şeklinden dolayı isim verilen başka peynirler de vardır. (Ögel, 1978: 30-31) Ancak Ögel'in görüşüne kaynaklık eden eser açık değildir.

Bu sözcük, Derleme Sözlüğ̈̈nde iremçik olarak yer almış olup, anlamı "peynir" olarak verilmiştir. (DS 1993: 2548) (krş. $\rightarrow$ Mo. örüme "scum on boiled milk, milk condensed to a hard substance by boiling it for a long time" (Lessing, s. 644a)

6. ḳatıg katık “ekmekle beraber yenilen süt yoğurt gibi şeyler” (Toparl1, 2007: 131) Kıpçak TZ katık "katık" 5a/2 (Atalay, 1945: 188); Kİ katık "ekmekle beraber yenilen süt yoğurt gibi şeyler" (Bu kelime Ebu Hayyan'a göre qatt1 kelimesinden çıkmıştır) 68 (Caferoğlu, 1931: 72); İM katı $\dot{g}$ "katık, yiyecek" 389a/1 (Toparl1, 1992: 548)

Tarihi: KökT.-, Uyg.-, DLT katık "sirke, yoğurt gibi tutmaç yemeğine katılan nesne" (DLT I, 382-11), Harezm ME-, NF-, KE-, Çağ. Seng. katı $\dot{g} /$ katık "çeşni”" $(267 \mathrm{r} / 29)$

Çağdaş Kıpçak: Tat.-, Başk. sey katık "kesilip koyulaşmış süt”" (BaşkRSI: 331), Kzk. katık "süzme yoğurt" (KzkRSl: 165), Nog. katık "süt" (NogRSl: 155), KBalk. katık "mandıra ürünleri” (KBalkRSl: 400), Kum. ak katık "mandıra ürünleri” (KumRS1: 196), Karay. k'atık' “ekşimiş süt” (KarayRS1: 366)

7. kaymạ̣ "kaymak" (Toparlı, 2007: 134) Kıpçak Kİ kaymak "kaymak" 77 (Caferoğlu, 1931: 74); KK kaymak "kaymak" 70b/7 (Toparlı, 1999: 112); TZ kaymak "kaymak" 29a/4 (Atalay, 1945: 189); GT kaymak "kaymak" 155/2; 171/7 (Karamanlıŏlu, 1989: 291); DM kaymak "kaymak" 6b/5 (Toparl1, 2018: 90); BV kaymak "kaymak (çiğ k.)" 67A/16 (Ăgar, 1986: 208) 
Tarihi: KökT.-, Uyg. kayak (BT IX(I), 155; 168v22), DLT ķayak "kaymakyenecek" (DLT III, 167-5), Harezm ME-, NF-, KE-, HŞ kaymak "kaymak" (Sulak, 2011: 303) Çağ. Seng. kaymak 281v/8; LÇT kaymak "süt üstünde olan kaymak" 226r/10; Courteille kaymak "sütte oluşan tabaka" 415

Clauson kelimenin kökünü *kañ- fiiline dayandırmıştır. Bu fiile gelen -ak eki ile beraber kelimenin *kanak biçimine dönüştüğünü öngörmüştür. Sonraki dönemlerde kelimenin gelişiminin *kaynak olması gerektiğini söylemiş fakat çağdaş dillerde kaymak olarak yaşadığını belirtmiştir. *Kanak kelimesinin anlamını "sütün üzerindeki deri, kaymak" olarak vermiştir. (EDPT: 636b)

Çağdaş Kıpçak: Tat. kaymak "kaymak" (TatRSl: 513), Başk. kaymak "ekşi krema” (BaşkRSl: 313), Kzk. kaymak "kaymak, sütün kaymă̆ı”" (KzkRSl: 155), Nog.-, KBalk.-, Kum. ķaymak “ekşi krema” (KumRSl: 180), Karay.-

8. kere yag் kere yav "tereyağ" (Toparl1, 2007: 139) Kıpçak TZ kere yav "tereyağ" 18a/9 (Atalay, 1945: 195); TA kere yag "tereyağı" 17b/9 (Toparlı, 2000: 116)

Tarihi Kıpçak sahası dışında başka tarihi dönemlerde görülmemiş olup, Çağdaş Kıpçak sahasında da yaşamamaktadır.

Misalli Büyük Türkçe Sözlük’te tereyağının Farsça kere kelimesinden geldiği, kere'nin anlamı unutulduğu için sonuna yağ eklendiği, "sütten elde edilen taze yağ" anlamına geldiği ve yeşillik anlamına gelen tere ile bir bağlantısının olmadığ 1 yazılmıştır. (Kubbealtı, 2005: 3166)

Gencine-i Güftar Ferheng-i Ziya'da kelime كره olarak yazılmış ve anlamına “tereyağı" denilmiştir. (Şükun, 1984: 1531)

9. kururut "bir tür peynir" (Toparl1, 2007: 164) Kıpçak Kİ kurut "bir nevi peynir" 70 (Caferoğlu, 1931: 83); TZ kurut "kurutulmuş yoğurt" 5a/3 (Atalay, 1945: 212); BM ḳurut, kurud "peynir türü” 11/6 (Zajaczkowski, 1958: 42)

Tarihi: KökT.-, Uygur. kurut "bir vergi türü” (Caferoğlu, 2011: 188); DLT kurut "keş, çökelek, yağı alınmış yoğurttan yapılan lor peyniri (DLT I, 357-2) ; KB kurut "peynir" (4442) ; Harezm ME-, NF-, KE-, Çağ. Seng. kurut 286r/23; Courteille kurut "çökmüş peynir altı suyu" 428; LÇT ḳurut "süt kurusu bir nevi peynir" 230r/1

Clauson kelimenin kökünün kurī- olduğunu ve fiilden isim yapan - $t$ eki alarak isme dönüştügünü belirtmiş, anlamını ise "sert bir peynir türü" olarak vermiştir. (EDPT: 648a) Berta kelimenin kökünü kurt- olarak vermiş ve anlamı için şöyle demiştir: "siyah peynir (kuru bir peynir çeşididir)" (Berta, 1996: 274) Marcel Erdal da Clauson'la aynı görüşte olup kelimenin kökünü kurl-'ya dayandırmış ve anlamını "kurutulmuş kuruttan yapılan peynir" olarak vermiştir. (OTWF I: 308) 
Hasan Eren kelimenin anlamını "kurutulmuş süt ürünü” olarak vermiştir ve kelimenin kökünü kuru-'dan getirmiştir. Türkçeden Moğolca, Farsça gibi dillere de geçtiğini belirtmiştir. (Eren, 1999: 270)

Çağdaş Kıpçak: Tat. korıt/kort "kurut" (TatRSl: 617) ; Başk. ķorot "kurut" (BaşkRSl: 339) ; Kzk. kurt "sütten yapılan kurutulmuş sert peynir" (KzkRSI: 182), Nog. kurt "tuzlu süzme peynir" (NogRS1: 189) ; KBalk.- ; Kum.- ; Karay.-

Kaşgarlı'nın sözlüğünde kurutluğ diye bir kelime daha vardır. Açıklaması "kurutu olan kimse" olarak yapılmıştır. Bu kelimenin sıfat haline gelmesi şüphesiz ki kurut'u olan kimsenin aç kalmayacağı düşüncesine olan inançtan gelir.

Bugün Anadolu'da kurut denince akla daha çok çökelek kurusu gelir. Aslında çökelik veya çökelek, peynir de değildir. Yağı alınmış yoğurdun kurusudur. Pallas, Timkovski ve Radloff gibi Orta Asya'da uzun araştırma gezilerine çıkmış olan bilginler kurut deyişinin iki manaya geldiğini söylemişlerdir. Birincisi; onlara göre yağı alınmış süte de kurut deniyordu. Asıl önemli olan ikinci anlayış ise; bu deyişin savaş azı̆̆ı için söylenmiş olması idi. Aslında ise bu, tam anlamı ile bir "kış azığı" demek idi. Kaşgarlı'nın açıklamalarından kurutun ne çeşit bir peynir olduğu açık olarak anlaşılamıyor. Besim Atalay ise daha çok Anadolu'dan edindiği bilgilerle keş, çökelek, yağı alınmış yoğurttan yapılan lor peyniri gibi geniş bir tercüme yapmak eğilimini göstermişti. Aslında lor peyniri ile çökelek aynı şeyler değildir. (Ögel, 1978: 33-34)

Bunun yanı sıra Kıpçakça'da kurutun bir çeşidi olarak kara kurut kelimesi de geçmektedir.

kara ḳurut "kara peynir, bir cins kuru peynir" (Toparl1, 2007: 126) Kıpçak Kİ kara kurut "siyah peynir" 70 (Caferoğlu, 1931: 70) ; BM kara kurut "siyah peynir (kuru bir peynir çeşidi)" 8/4 (Zajaczkowski, 1958: 38)

Tarihi: KökT.-, Uygur.- ; Harezm-; Çağ. Courteille ḳara ḳurut "kurumuş peynir altı suyu" 397

Clauson bu kelimenin anlamını şöyle açıklamıştır "Kurut yapılan kesilmiş suyun sütü pıhtılaşıncaya kadar tekrar ve tekrar kaynatılır. Tahmin edilemeyecek kadar ekşi ve kurudur. Kan basıncını düşürür” Ayrıca kelimenin eş anlamlısının çakıltak olduğunu fakat Senglah'dan önceki dönemde görülmediğini belirtir. (EDPT: $648 b)$

Kara kurut kelimesine Çağdaş Kıpçak dillerinde rastlanmamıştır.

10. lor Fa. Kıpçak Kİ lor "keçi veya koyun doğurduktan sonra üç gün zarfinda onun sütünden yapılan peynir" 87 (Caferoğlu, 1931: 57) ; BV lor "bir bitki(?)" 64A/25 (Ăgar, 1986: 233) 
Tarihi Kıpçak sahası dışında başka tarihi dönemlerde görülmemiş olup, Çağdaş Kıpçak sahasında da yaşamamaktadır.

Bu kelime Farsça-Türkçe bir sözlük olan Gencine-i Güftar Ferheng-i Ziya'da şu şekilde geçmektedir: لور "lor dediğimiz taze, tuzsuz peynir" Bu açılamadan sonra şu örnek verilmiştir. "Şeker ve sütten daha tatlı ve yağlısın; lor ve peynirden daha yumuşak ve naziksin” (Şükun, 1984: 1757)

11. peynīr penīr benir beynir Trm. "peynir" Kıpçak Kİ bäynir "peynir" 36 (Caferoğlu, 1931: 17) ; pänir "peynir" 36 (Caferoğlu, 1931: 67) ; DM peynir "peynir" 6b/5 (Toparl1, 2018: 102) ; KK beynir "peynir" 70b/2 (Toparl1, 1999: 121) ; TA penir "peynir" 17b/3 (Toparl1, 2000: 133) ; TZ peynir "peynir" 11b/11 (Atalay, 1945: 229) ; BM päjnir "peynir" 8/1 (Zajaczkowski, 1958: 37)

Tarihi: KökT.-, Uyg.-, DLT-, Harezm ME-, NF-, KE-, Çağ. Courteille penir "peynir" 160

Çağdaş Kıpçak: Tat.-, Başk.-, Kırg.-, Kzk.-, Nog.-, KBalk.-, Kum.-, Karay. penir "peynir" (KarayRSl: 450)

Peynir sözcüğü aslında Türkçe bir deyiş değildir. Türkçeye Farsçadan girmiştir. İlk defa Mısır Memluklerinin Türkçe sözlükleri ile Eski Anadolu Türkçesi metinlerinde görülür. Mısır'da yazılmış sözlüklerde benir, penir, beynir gibi Farsça formlarda da görülürler. (Ögel, 1978: 30) Peynir anlamına gelen ve Türkçe olan pek çok kelime varken, Farsça kökenli kelimenin günümüz Türkçesinde tercih edilmesi düşünülmesi gereken bir konudur.

Bu kelime Gencine-i Güftar Ferheng-i Ziya'da kısa bir açıklama ile verilmiştir. “بنيب "peynir dediğimiz” (Şükun, 1984: 502)

12. pışlaḳ bışlak "kurutulmuş yoğurt" (Toparlı, 2007: 216) Kıpçak TZ pışlak "kurutulmuş yoğurt" 5a/3 (Atalay, 1945: 229)

Tarihi: KökT.-, Uyg.-, DLT-, Harezm ME bışlak "peynir” (Poppe, 2009: 175), NF-, KE-, Çağ.-

İlk kez İbn-i Mühenna lugatinde görülmüştür. Peynir sözcügünü karşılayan en eski sözcüktür. İbn-i Mühenna lugatinde kelime madde başı olarak bışlak biçiminde verilmiştir. Kelimenin Moğolcada da "peynir" anlamında kullanıldığ ve bu lügatin Moğolca kısmında da yer aldığı parantez içinde belirtilmiştir. (Battal, 1934: 21)

Çağdaş Kıpçak: Tat. pışlak "peynir, peynir türü” (TatRSl: 170), Başk.-, Kzk.-, Nog. puslak "peynir” (NogRSl: 273), KBalk. bışlaq "peynir” (KBalkRSl: 175), Kum. bişlaq "peynir" (KumRSl: 79), Karay. - 
Bu sözcük Afyon Emirdağ ve Konya'da eski geleneklerinin büyük bir bölümünü yaşatan Karaçay aşiretinde aslına sadık kalarak peynir yerine kullanılmaktadır. (DS 1993: 670)

13. sag̉ay șag்yag் saru yag் sarya $\dot{g} \sim$ sayag "tereyağı" (Toparl1, 2007: 227) Kıpçak Kİ sag்yag "sade yağ yani sütten çıkan yağ" 58 (Caferoğlu, 1931: 85) ; KK șarl yag "tereyağı” 70b/6 (Toparl1, 1999: 121) ; RH șaru yag 91a/9 ; 92a/1 ; 95b/3 ; 96a/7 ; 97a/5 (Delice, 2003: 261) ; TA șayag “tereyağı” 17b/10 (Toparl1, 2000: 136) ; BM șajay “tereyă̆ı” 8/6 (Zajaczkowski, 1958: 44)

Tarihi: KökT.-, Uyg. sağ yă̆ “tereyağı"'(Caferoğlu, 2011: 193), DLT să̆ yă̆ “sadeyağ, sağyă̆” (DLT III, 154-11), Harezm ME-, NF sag yag் "tereyağı” (Ata, 1998: 357), KE-, Çağ.-

Clauson sā̆g kelimesi için ilk dönemlerde saf, katışıksız anlamına geldiğini belirtmiştir. $\mathrm{Bu}$ bağlamda kullanılan săğ yăğ "saf, katışıksız yağ" anlamına gelmektedir. Fakat daha sonra kelime anlam değişikliğine uğramış ve "sağlıklı, salim" anlamına gelmiş; daha sonra ise şaşırtıcı bir anlam değişikliğine uğrayarak "sol olmayan, sağ" anlamına gelmiştir. (EDPT: 803a)

Çağdaş Kıpçak: Tat. sarı may “eritilmiş yağ” (TatRSl: 219), Başk. -, Kzk. sarımay "tereyağı" (KzkRSl: 400), Nog. sarl may "tereyağı" (NogRSl: 210), KBalk. sarı djay "tereyağı" (KBalkRSl: 235), Kum. sari may "inek sütünden yapılan saf yağ” (KumRS1: 222), Karay. sart yav "tereyağı” (KarayRS1: 214)

Să̆ yă̆ gibi çok eski bir özlük taşıyan Türk deyişleri de Anadolu'da yaygın olarak kullanılmıştır. Kıpçak Türkçesi ve Eski Anadolu Türkçesinde sarı yă̆ deyimi yaygın olarak eritilmiş veya taze olarak elde edilmiş inek yağlarına denmiştir. (Ögel, 1978: 14)

14. süt "süt" (Toparlı, 2007: 246) Kıpçak Kİ süt "süt” 51 (Caferoğlu, 1931: 95) ; KK süt "süt" 70b/10 (Toparl1, 1991: 123) ; RH süd "süt" $94 b 7$; $95 b 5$ (Delice, 2003: 263) ; TA süt "süt" 17b/2 (Toparl1, 2000: 141) ; BM süt, süd "süt" 8/2 (Zajaczkowski, 1958: 48) ; TZ süt "süt" 13a/11 ; 31b/12 (Atalay, 1945: 244) ; GT süt "süt" 28/5 (Karamanlığlu, 1989: 362) ; DM süt "süt" 4b/6 (Toparl1, 2018: 108) ; İM süt “süt" 105a/1 (Toparl1, 1992: 595) ; KF süd "süt" 101a/2 (Kuanişbayev, 2006: 181) ; BV süt "süt” 14A/2 ; 14B/5 ; 24A/9;24A/12 ; 24B/1 ; 43B/18 ; 67B/25 ; 68B/6 (Ăgar, 1986: 287) ; KFT süd "süt" 386b/21 (Ağar, 1989: 1063)

Tarihi: KökT-, Uyg. süt "süt” (Gabain, 2007: 295), DLT süt "süt” (DLT III, 12018), KB süt "süt" (881, 4442, 5881), Tefsir süt "süt" (Usta, 2002: 242), Harezm ME süt "süt" 54-3 (Yüce, 1988: 180), NF süt "süt" (Ata, 1998: 385), KE-, HŞ süt "süt" (Sulak 2011: 349); Çağ. Abuşka süt "süt" 285/2 (Atalay, 1970: 285); Courteille süt/süd "süt” 351; LÇ süt "süt” 188r/11; Abuşka süt "süt” 285/2 
Clauson'da kelime uzun ünlülü olarak sǖt biçiminde gösterilmiştir. Sondaki -t'nin -d olabileceği parantez içinde belirtilmiştir. (EDPT: s.798b) Moğolca sün ile yakınlığını belirtmişlerdir. (TMEN: s.771)

Hasan Eren'e göre Moğolca sün'ün, Türkçe süt biçimi ile ses ve yapı yönlerinden açıklanamaz. Bilimsel yayınlarda sondaki - $t$ 'nin çokluk eki olabileceği üzerinde durulduğunu söyler. Bu ekin Moğolca olduğunun açık bir gerçek olduğunu fakat Türkçede kullanılan süt ürünlerinin son seslerinin - $t$ ile bitmesinin de göze çarptığını söyler. (Eren, 1999: 456; 380)

Çağdaş Kıpçak: Tat. söt "süt” (TatRSl: 255), Başk. höt "süt" (BaşkRSl: 635), Kzk. süt "süt" (KzkRSl: 250), Nog. süt "süt” (NogRSl: 316), KBalk. syut "süt" (KBalkRS1: 592), Kum. syut "süt” (KumRSl: 297), Karay. sit/süt/syut "süt" (KarayRSl: 476, 502)

Türkçenin en eski kaynakları incelenirken süt sözcügüne ilk kez Uygur metinlerinde rastlanmakta, bu kaynaklardan bu yana bütün Türk lehçelerinde aynı sözcükle karşılaşılmaktadır. (yalnızca Yakutça $\bar{u} t$, Başkurtça höt biçimleri sesçe farklılık gösterse de, bu farklılıklar söz konusu diller için tipik özelliklerdir.) Karahanlı Türkçesinin zengin söz varlığını 11. yüzyılda bütün ayrıntılarıyla ortaya koyan Divan'da süt, değişik anlatım biçimleriyle yer almaktadır. Örneğin süt kayaklandı "kaymaklandı", süt soguldu "çekildi”, sütler koyluşdı "koyulaştı", tatındı süt "bol süt", bir sagım süt "bir sağmada alınan süt" gibi... Divan' da geçen bir atasözü insanlara kötülük eden kimselere bile iyilikle karşılık verilmesini ögütler: Suv içürmesge süt ber "su içirmeyene süt ver" (Aksan, 2008: 118)

15. süzme (2) "süzülmüş yoğurt” (Toparl1, 2007: 247) Kıpçak Kİ süzmä “süzülmüş yoğurt” 52 (Caferoğlu, 1931: 95) ; İM süzme "süzülmüş” 387a/7 (Toparl1, 1992: 595)

Tarihi: KökT.-, Uyg.-, DLT süzme "keş dedikleri yağsız kuru peynir, ayran süzmesi (DLT I: 433-22) Harezm ME süzme “ekşimik” (Poppe, 2009: 178), NF-, KE-, Çağ.-

Clauson kelimenin kökünü süz- olarak vermiştir ve kelimeyi fiilden isim/sıfat olarak değerlendirmiştir. Çağdaş dillerde bu kelimenin "kurut, peynir ya da yağı alınmış süt" anlamlarında kullanıldığını belirtmiştir.

Ayrıca Tuhfetu'z-Zekiyye'de bu anlamda geçen bir kelime daha vardır. Kıpçak dönemi eserlerinden sadece Tuhfetu'z-Zekiyye'de geçmiş olup ne tarihi dönem ne de modern dönemde bu kelimeyle karşılaşılmıştır. Kıpçak TZ süzmeli "süzülmüş yoğurt” 32a/1 (Atalay, 1945: 244)

Çağdaş Kıpçak: Tat. sözme "syuzma” (TatRS1: 250), Başk. höżme "ekşi süt" (BaşkRS1: 630), Kzk. süzbe "süzülen yoğurt, bir nevi beyaz peynir" (KzkRSl: 
248), Nog. süzbe "süzme peynir türü” (NogRSl: 314), KBalk. syuzme bışlak "süzme peynir" (KBalkRSl: 589), Kum.-, Karay.-

16. turak "koyulaşmış süt" (Toparlı, 2007: 284) Kıpçak Kİ turaq "koyulaşmış süt” 62 (Caferoğlu, 1931: 107)

Tarihi: KökT.-, Uyg.-, DLT-, Harezm-, Çağ. Courteille turak "peynir” 225

Kitab-1 Mecmu-1 Tecüman-1 Türki ve Acemi ve Mugali'de bu kelime için iki farklı anlam daha verilmektedir. Bunlar "yoğurttan yapılmış baharatlı bir yemek" ve "yoğurtla yapılan bir yemek" anlamlarıdır. Houtsma kelimenin anlamını "doğranmış salatalıkla kuruttan yapılan salata" olarak vermiştir ve Türkmenlerin bu anlamda kullandıklarını söylemiştir. (Berta, 1996: 380)

Clauson kelimeyi turuk olarak vermiştir. Anlamını ise "bekletilmiş süt" veya "kurut" olarak kaydeder. (EDPT: 538b)

Bu kelime Çağdaş Kıpçak sahasında görülmemektedir.

17. uygan "yağı alınmış yoğurt" (Toparlı, 2007: 295) Kıpçak TZ uygan "yağı alınmış yoğurt" 31b/2 (Atalay, 1945: 272)

uyup "sulu yoğurt" (Toparl1, 2007: 296) Kıpçak TZ uyup "sulu yoğurt" 31b/12 (Atalay, 1945: 272)

$\mathrm{Bu}$ iki kelime başka hiçbir tarihi dönemde karşımıza çıkmamıştır. Çağdaş Kıpçak sahasında da görülmemektedir. Fakat kelimelerin kökeninin uyu-'dan geldiği aşikardır.

Sütün pişirilip ılıdıktan sonra maya katılıp bekletilmesi işlemi uyutmak olarak adlandırılmıştır. Batı, İç ve Kuzey Anadolu'da yoğurt yapmak üzere sütü mayalamak uyutmak olarak anlatılırken, sütle yapılan bir yemeğe uyutma denmektedir. (Aksan, 2008: 124)

Derleme sözlüğünde ise aynı kökten gelen ve yoğurt anlamında verilen pek çok kelime mevcuttur: "uyun, uynuk" Yine yoğurdu mayalamak anlaminda da “uyutmak" kelimesine Derleme Sözlüğü’nde rastlarız. (DS: 4050-4051)

18. yag்urt $\sim$ yavurt $\sim$ yog்urt $\sim$ yog்urud çuġrat "yoğurt" (Toparl1, 2007: 53,328) Kıpçak Kİ yag்urt "yoğurt” 95 (Caferoğlu, 1931: 117) ; Kİ çugrrat "yoğurt" 43 (Caferoğlu, 1931: 31) ; KK yog்urt "yoğurt" 70b/12 (Toparl1, 1999: 131) ; RH yog்urt "yoğurt" 97b/1 (Delice, 2003: 274) ; TA yag்urt "yoğurt" 17b/1 (Toparlı, 2000: 153) ; BM jayurt "pıhtılaşmış süt" 8/3 (Zajaczkowski, 1958: 23) ; TZ yavurt "yoğurt" 31b/13 (Atalay, 1945: 282) ; GT yug்urt "yoğurt" 85/2 (Karamanlıŏlu, 1989: 399) ; DM yag்urt "yoğurt” 4b/6; 6b/7 (Toparl1, 2018: 108) ; BV yog்urt "yoğurt" 48A/2 (Ăgar, 1986: 351) ; KFT yog்urud "yoğurt" 268a/24 (Ağar, 1989: 1099) ; MS yog்urt "yoğurt" 9b/2 (Toparl1, 1987: 103) 
Tarihi: KökT.-, Uyg. yog்urt, yorgurd, yogrot "yoğurt" (Gabain, 2007: 312)(Caferoğlu, 2011: 301), DLT yogurt "yoğurt" (EDPT: 905b), KB yuğrut "yoğurt” (4442), Harezm ME-, NF-, KE-, Çağ.-

Divan-1 Lugatı't-Türk'te kelime madde başı olarak yer almaz ancak uḍış-, sütger-, udit-, kat-, koyul- , suwuk maddeleri altında örneklerde yer almıştır. (EDPT: 905b)

Clauson'da kelime yuğrut olarak yer almıştır. Kelimenin kökünü yuğur-‘a dayandırır ve fiilden türemiş isim olduğunu söyler. Anlamını ise "kesilmişs süt, yoğurt" olarak vermiştir. Orta dönemde kelimenin metateze uğrayarak yuğurt biçimine dönüştüğünü ifade etmiştir. (EDPT: 905b)

Tezcan ise kelimenin kökünü *yog- olarak ifade etmiştir. Yogun kelimesinin anlamının kalın olduğunu söyleyerek, *yog- fiilinin de kalınlaşmak anlamına gelebileceğini ifade etmiştir. Dolayısıyla yoğurt kelimesinin etimolojisini şu şekilde düşünmüştür: <*yog-ur-ut (Erdal, 1991: 313)

Hasan Eren yoğurt kelimesinin anlamını "maya katılarak koyulaştırılmış süt" olarak vermiştir. Kelimenin kökünü yuğur-'a dayandırmıştır. - $t$ eki ile isim olduğunu söylemiştir. Türkçe yoğurdun Rumence urda "yağı alınmış sütten yapılan peynir" biçimiyle birleştirilmesinin yanlış olduğunu söylemiştir. (Eren, 1999: 4555)

Çağdaş Kıpçak: Tat. yogurt "yoğurt” (TatEng: 24), Başk.-, Kzk.-, Nog. yuvırt "ekşimiş süt, kesilip koyulaşmış süt" (NogRSl: 445), KBalk.-, Kum. yuvurt "yoğurt, ekşimiş süt” (KumRSl: 381), Karay.-

Aksan kelimenin kökeninin yuğur- ile bağdaştırılmasının güç olduğunu söyler. Çünkü yoğurdun yapılışı göz önünde bulundurulduğunda yuğurma eylemiyle ilgisi yoktur. Yoğurtla ilgili en çok dil gereci, yine 11. yüzyılda Divan'da bulunur. $\mathrm{Bu}$ kaynakta hem yoğurdun niteliklerine hem de türlerine ilişkin kayıtlar bulunmaktadır. Sütü mayalayarak dinlenmeye bırakma işlemi uyutmak eylemiyle anlatılmıştır. Sulu yoğurt için suwuk yoğurt tamlaması, yoğurdun koyulaşması için koyulmak eylemi kullanılmıştır. Su katarak sulandırmaya ise sütgermek denilmiştir. (Aksan, 2008: 123-124)

A. Ünsal'a göre, yoğurdu ilk Türklerin bulmuş olmasına rağmen uluslararası arenada sütü yoğurda dönüştüren bakterinin "lactobacillus bulgaricus" adiyla anılıyor olmasında tanıtımda geç kalmamız sebebiyle kabahatimiz büyük. (Ünsal, 1997: 23) Yoğurt Avrupalıların zannı gibi Bulgar mahsulu icadı değildir. Türkler ve Doğu milletleri ile her temasa gelen millet, temaslarının eskiliği nispetinde bunu yapmayı öğrenmişler ve kullanmışlardır. Türkün ana yurtta öz malı olan yoğurt için gösterilen bu misaller yoğurt tarihini ve onun Avrupaca bilinmeyen mazisini aydınlatacak kadar eski ve kıymetlidir. (Ünver, 1936: 3) 


\section{SONUÇ}

Kıpçak Türkçesi ile yazılmış eserlerde süt ve süt ürünleri ile ilgili kelimeler incelenmiştir. Bunun sonucunda;

1. Moğolca olduğu şüpheli olan iki kelimeye (plşlak, ayran); üç tane Farsça kelimeye (göremez, lor, peynir); bir tane bir unsuru Farsça olan kelimeye (kereyağ); bir tane Osetçe olduğu sanılan kelimeye (çıkıt) rastlanmıştır. Geri kalan kelimeler Türkçedir.

2. Kelimelerin bazılarına Çağdaş Kıpçak sahalarında rastlanmıştır. Bunun dışında bu kelimeleri karşılayan başka kelimeler olduğu da tespit edilmiştir. (Kırg. çalap "ayran”, Kzk. şalap “ayran”)

3. Süt ve süt ürünlerinin kullanıldığı dönem olarak en fazla çeşitliliği içeren dönemin Kıpçak Türkçesi dönemi olduğu görülmüştür. Diğer tarihi sahalarda konuyla ilgili olarak Kıpçakça'da olduğu kadar kelime çeşitliliğine rastlanmamıştır.

4. Kelimelerin iki tanesi hapaks örneklerdir. Ne tarihi dönemde ne de modern Kıpçak döneminde bir daha görülmemiştir. Aynı kökten olduğu düşünülen örnekler Derleme Sözlüğü'nde yer almıştır. (bkz. uygan ve uyup)

5. Kelimelerden on tanesi Türkiye Türkçesinde, tarihi dönemde kullanılan anlamlarıyla yaşamaktadır. (ăgız, ayran, kaymak, kurut, lor, peynir, süt, yoğurt, süzme, kereyag/tereyag)

\section{KAYNAKÇA}

AĞAR, M.Emin. (1986), Baytaratu'l-Vazıh, Yüksek Lisans Tezi, Marmara Ünv. Sosyal Bilimler Enstitüsü

AĞAR, M.Emin. (1989), Kitab-u fi'l-Fıkh bi-Lisani't-Türki (Inceleme-MetinSözlük), Doktora Tezi, Marmara Ünv. Sosyal Bilimler Enstitüsü

AKSAN, Doğan. (2008), Türkçeye Yanslyan Türk Kültürü, İstanbul: Bilgi Yayınevi

ARAT, R.R. (1979-1985), Kutadgu Bilig/Yusuf Has Hacib, Ankara: TDK

ATA, Aysu. (1997), Kısasü'l-Enbiya (Peygamber Klssaları): Dizin/Burhanoğlu Kadı Nasiruddin, Ankara: TDK

ATA, Aysu. (1998), Nehcü'l-Feradis, Uştmahlarnıng Açuk Yolu, Dizin-Sözlük, Ankara: TDK 
ATALAY, Besim. (1945), Et-Tuhfetü'z-Zekiyye fi'l-Lugati't-Türkiyye, Ankara: TDK

ATALAY, Besim. (1970), Abuşka Lugati veya Çă̆atay Sözlüğ̈̈, Ankara: Ayyıldız Matbaas1

ATALAY, Besim. (1985-1986), Divanu Lugatı't-Türk Tercümesi, C I-V, Ankara: TDK

AYVERDİ, İlhan. (2005), Kubbealtı Lugatı Misalli Büyük Türkçe Sözlük, C I-III, İstanbul

BAMMATOV, Z.Z. (1969), Kumıksko Russkiy Slovar', Moskva

BASKAKOV, N.A. (1963), Nogaysko Russkiy Slovar', Moskva

BASKAKOV, N.A., S.M Szapzal, A. Zajaczkowski. (1974), Karaimsko-RusskoPol'skiy Slovar', Moskva

- (1958) Başkirsko-Russkiy Slovar', Moskva

BATTAL, Abdullah. (1934), İbnü-Mühenna Lugati, İstanbul: Devlet Matbaası

BEKTAEV, Kaldıbay. (2001), Kazaksko Russkiy Slovar'

BERTA, Arpad. (1996), Deverbale Wortbildung im MittelkiptschakischenTürkischen, Wiesbaden

BOROVKOV, A.K. (2002), Orta Asya'da bulunmuş Kur'ân tefsirinin söz varlı̆̆ (XII.-XIII. yüzyıllar), Çev. H.İ. Usta, Ankara: TDK

CAFEROĞLU, Ahmet. (1931), Abu Hayyan, Kitab al-İdrak li-lisan al-Atrak, İstanbul

CAFEROĞLU, Ahmet. (2011), Eski Uygur Türkçesi Sözlüğ̈̈, Ankara: TDK

CLAUSON, Sir Gerard. (1972), An Etymological Dictionary of Pre-Thirteenth Century Turkish, Oxford

- (1960) Muhammad Mahdi Xān, A Persian Guide to the Turkish Language, London: GMS, New Series XX

COURTEILLE, Pavet de. (1870), Dictionnaire Turc-oriental, Paris

ÇAĞBAYIR, Yaşar. (2007), Ötüken Türkçe Sözlük, 5c., İstanbul: Ötüken Neşriyat DELİCE, İbrahim. (2003), Hulasa Okçuluk ve Atçılık, İstanbul: Kitabevi Yayınları

DOERFER, Gerhard. (1963-1975), Türkische und Mongolische Elemente im Neupersischen, 4c., Wiesbaden 
DS: (1993) Türkiye’de Halk A ğzından Derleme Sözlüğü, XI C., Ankara: TDK

ERDAL, Marcel. (1991), Old Turkic Word Formation, A Functional Approach to the Lexicon, C. I-II, Wiesbaden

EREN, Hasan. (1999), Türk Dilinin Etimolojik Sözlüğ̈̈, Ankara: Bizim Büro Basımevi

GABAIN, A. Maria. (2007), Eski Türkçenin Grameri, Çev. Mehmet Akalın, Ankara: TDK

IŞITMAN, İ.R. (1941), Muhakemetu'l-Lugateyn/Ali Şir Nevayi, Ankara: TDK

İZBUDAK, Veled. (1989), el-İdrak Haşiyesi, Ankara: TDK

LESSING, F.D. (2003), Moğolca-Türkçe Sözlük: A-N, Çev. Günay Karaağaç, Ankara: TDK

KARAMANLIOĞLU, Ali Fehmi. (1989), Seyfi Sarayi, Gülistan Tercümesi, Ankara: TDK

KUANIŞBAYEV, Ercan. (2006), Kitab-ı fi'l fikh (giriş-metin-dizim-tıpkıbasım), Doktora Tezi, Marmara Ünv. Türkiyat Araştırmaları Enstitüsü

ORALTAY, Hasan, N. Yüce, S. Pınar. (1984), Kazak Türkçesi Sözlüğü, İstanbul: Türk Dünyası Araştırmaları Vakfı

ÖGEL, Bahaeddin. (1978), Türk Kültür Tarihine Giriş 4, Ankara: Kültür Bakanlığı Yayınları

POPPE, Nicholas. (2009), Mukaddimetu'l-Edeb: Moğolca-Çağatayca Çevirinin Sözlüğü, Çev. Mustafa Kaçalin, Ankara: TDK

SULAK, Salih. (2011), Kaynaklardan Ders Kitaplarina Aktarma: Kutb'un Husrev ü Şirin'inin Metin, Çeviri ve Sözlüğ̈̈, Yüksek Lisans Tezi, Marmara Ünv. Eğitim Bilimleri Enstitüsü Türkçe Eğitimi Anabilim Dalı

Şeyh Süleyman Efendi-yi Buhari. (1882), Lugat-i Çaġatay ve Türki-yi Osmani, İstanbul: Mihran Matbaas1

ŞÜKÛN, Ziya. (1984), Gencine-i Güftar Ferheng-i Ziya, Istanbul: MEB Basımevi

TENIŞEV, E.R., X.İ. Süyünç. (1989), Karaçaevo-Balkarsko Russkiy Slovar', Moskva

TOMAH, Dvuh. (2007), Tatarsko-Russkiy Slovar', 2 c., Kazan

TOPARLI, Recep. (1987), Kitab-ı mukaddime-i Ebü'l-Leys es-Semerkandi/Ebü'lLeys Imamülhüda Nasr b. Muhammed b. Ahmed Semerkandi, Atatürk Üniversitesi Fen Edebiyat Fakültesi, Erzurum 
TOPARLI, Recep. (1992), İşadü'l-Mülük ve's-Selatin, Ankara: TDK

TOPARLI, Recep. (2018), ed-Dürretü'l-mudiyye fi'l-lugati't-Türkiyye, Ankara: TDK

TOPARLI, Recep, S. Çöğenli, N. Yanık. (1999), El-Kavaninü'l-külliyye li zabti'llügati't-Türkiyye, Ankara: TDK

TOPARLI, Recep, S. Çöğenli, N. Yanık. (2000), Kitab-ı mecmu-ı tercüman-ı Türki ve acemi ve mugali, Ankara: TDK

TOPARLI, Recep, H. Vural, R. Karaatl1. (2007), Kıpçak Türkçesi Sözlüğü, Ankara: TDK

- (1993) Türkiye’de Halk Ağzından Derleme Sözlüğ̈̈, 12 c., Ankara: Ankara Ünv. Basımevi

ÜNSAL, Artun. (1997), Süt Uyuyunca, Istanbul: Yapı Kredi Yayınları

ÜNVER, Süheyl. (1936), Türklerde Yoğurdun Eskiliği Hakkında Birkaç Kelime, Istanbul: Tedavi Kliniği Yayınları

YUDAHIN, K.K. (1957), Orusça Kırgızça Sözdük, Moskva: Kırgız CCR İlimder Akademiyas1

YÜCE, Nuri. (1988) Mukaddimetü'l-Edeb, Giriş, Dil Özellikleri, Metin, Indeks, Ankara: TDK

ZAJACZKOWSKİ, A. (1958), Vocabulaire Arabe-Kiptchak de l'epoque de l'Etat Mamelouk, Bulgat aş-Muşstaq fi lugat at-Turk wa'l-Qlfçak, 1l- ere partie, Warszawa: Le nom

\section{KISALTMALAR}

Abuşka: Abuşka Lugati

BaşK: Başkurtça

BM: Kitabu Bulgatu'l-Müştak Fi Lugati't-Türk ve'l-Kıfçak

BV: Baytaratu'l-Vazıh

Çağ: Çağatayca

DLT: Divan-1 Lugatı't-Türk

DM: Ed-Durretu'l-Mudiyye Fi'l-Lugatı't-Türkiyye

DS: Derleme Sözlüğü

EDPT:An Etymological Dictionary of Pre-Thirteenth Century Turkish

GT: Gülistan Tercümesi 
HŞ: Husrev u Şirin

İH: El-İdrak Haşiyesi

İM: İrşadu'l-Mülük ve's-Selatin

Karay: Karayca

KB: Kutadgu Bilig

KBalk: Karaçay-Balkarca

KE: Kısasu'l-Enbiya

KF: Kitab fi'l-Fikh

KFT: Kitab Fi'l-Fıkh bi'l-Lisani’t-Türki

Kırg: Kırgızca

Kİ: Kitabu'l-İdrak li-Lisani'l-Etrak

KK: El-Kavaninu'l-Külliyye li-Zabti'l-Lugati't-Türkiyye

Kökt. Köktürkçe

Kum: Kumukça

Kzk: Kazakça

LÇ: Lugat-i Çağatay ve Türki-yi Osmani

ME: Mukaddimetu'l Edeb

MS: Kitab-1 Mukaddime-i Ebu'l-Leysi's-Semerkandi

NF: Nehcü'l-Feradis

Nog. Nogayca

RH: Kitab fi Riyazati'l-Hayl

Seng. : Senglah

TA: Kitab-1 Mecmu'-1 Tercüman-1 Türki ve Acemi ve Mugali

Tat. : Tatarca

Trm.: Türkmence

TZ: Et-Tuhfetü'z-Zekiyye fi'l-Lugatı't-Türkiyye

Uyg.: Uygurca 